Santa Clara University

Scholar Commons

Psychology

College of Arts \& Sciences

$12-1988$

\title{
Introducing the Living with Illness Group: A specialized treatment for patients with chronic schizophrenic conditions
}

Thomas G. Plante

Santa Clara University, tplante@scu.edu

Stephanie L. Pinder

David Howe

Follow this and additional works at: http://scholarcommons.scu.edu/psych

Part of the Clinical and Medical Social Work Commons, Clinical Psychology Commons, Cognitive Behavioral Therapy Commons, Community Psychology Commons, Counseling Psychology Commons, Health Psychology Commons, Medical Education Commons, Pain Management Commons, and the Psychiatric and Mental Health Commons

\section{Recommended Citation}

Plante, T. G., Pinder, S. L., \& Howe, D. (1988). Introducing the Living with Illness Group: A specialized treatment for patients with chronic schizophrenic conditions. Group, 12, 198-204.

The final publication is available at Springer via http://doi.org/10.1007/BF01419650.

This Article is brought to you for free and open access by the College of Arts \& Sciences at Scholar Commons. It has been accepted for inclusion in Psychology by an authorized administrator of Scholar Commons. For more information, please contact rscroggin@scu.edu. 


\title{
Introducing a Group Social Skills Training Program for Patients with Schizophrenic Symptoms
}

\author{
Thomas G. Plante, Ph.D. \\ Departments of Psychology and Psychiatry \\ Yale University
}

Running Head: Social Skills Training

The author would like to thank Stephanie L. Pinder, Ph.D., Seth R. Segall, Ph.D., and Jerry Singer, Ph.D. for their assistance with this project. Reprint requests should be addressed to Thomas G. Plante, Ph.D., Department of Psychology, Yale University, Box $11 \mathrm{~A}$ Yale Station, New Haven, CT 06520-7447.(203) 432-4606. 
Social Skills Training

Abstract

The purpose of this paper is to provide psychiatric nurses and other group therapists with a practical and detailed format for conducting social skills training for patients experiencing chronic schizophrenic symptoms. This program was developed and utilized at the Day Hospital in the Division of Psychiatry at Waterbury Hospital Health Center, Waterbury, CT. Principles of social skills training as well as specific treatment approaches are discussed in detail. Furthermore, examples of typical social skills training sessions are provided. 


\section{Introducing a Group Social Skills Training Program for}

\section{Patients with Schizophrenic Symptoms}

The goal of group social skills training is to help patients learn, practice and develop the skills necessary to effectively interact with others. Developing these skills results in improved enjoyment of relationships and reductions in the anxiety, depression, and stress associated with a large number of psychiatric conditions. Group social skills training is a highly effective adjunct treatment approach for patients experiencing chronic schizophrenic symptoms (Monti, Corriveau, \& Curran, 1982; Monti, Curran, Corriveau, DeLancey, \& Hagerman, 1980). Not only does social skills training assist patients in developing and practicing the skills which will help them get along better with relatives, friends, coworkers, and others, but also in helping build self-esteem, self-confidence, and general coping skills. With improved skills in dealing with others, these patients are more likely to maintain satisfying relationships as well as enhancing their chances of obtaining and maintaining gainful employment. They are also better equipped to conduct and complete daily living skills such as shopping and practicing good hygiene. Although social skills treatment can be conducted on an individual basis, group treatment is likely to be more effective (Monti et al., 
1982) .

Who Should Receive Group Social Skills Training?

Group social skills training is an appropriate adjunct treatment for a wide variety of psychiatric patients who experience the following symptoms:

(1) A chronic difficulty starting and maintaining relationships with others.

(2) Chronic experiences of stress, anxiety, nervousness, and/or discomfort interacting and being with others.

(3) An exacerbation of psychiatric symptoms while in the company of particular people or among people in general.

This form of treatment is especially designed to assist those who are in the chronic rather than acute stage of their illness.

\section{Principles of Group Social Skills Therapy}

Structure, support and focusing on the "here and now" are the three principles of group social skills therapy and are the most critical ingredients in effective group psychotherapy with this population (Yalom, 1983). Structure is provided by the following group rituals:

(1) Always start and end the group sessions on time. 
(2) Begin each group session with introductions and state the purpose of the group. One suggestion includes having each patient introduce him or herself and then name all of the previously introduced group members. This typically enjoyable exercise not only helps patients remember the names of fellow group members, but also provides a pleasant avenue for learning the social skills involved in meeting and greeting others.

(3) Ask the veteran group members to describe the purpose and activities of the group to any new group members. (4) Inquire about any group members who are not in attendance. This provides the message that all group members and group sessions are valuable and that missing members are noticed and missed.

Support is provided by the following:

(1) Every group member is strongly encouraged to participate in the group activities and discussions. (2) Every contribution by group members is supported and reinforced. Even poor performance and failure is reframed in order to emphasize the positive aspects of the patient's contribution.

(3) Group members are periodically reminded that social skills are skills that everyone can learn to develop and improve. Trying to learn is half the battle and making mistakes is inevitable.

Focusing on the "Here and Now" is conducted by the following: 
(1) Maximize the use of role plays as much as possible. Each role play is discussed after it is completed by the group members highlighting the positive aspects of the exercise.

(2) Discuss topics that group members have been having difficulty with within the past few days or anticipate having difficulty with during the upcoming few days (e.g., meeting a new boss, job interview, going on a date, family gathering, asking someone for a favor).

(3) Avoid discussions concerning medications, symptoms, or problems from the distant past or distant future during the group sessions.

\section{Treatment Formats}

There are two treatment formats that are useful in conducting the sessions. The first approach is the Anenda Taking approach and the second is the Themes and Topics approach. A combination of these two approaches can also be utilized. For example, the therapist could alternate between each approach on a monthly basis.

\section{Agenda Taking Approach}

After group introductions are made, the therapist asks the group if they have had any difficulties getting along with other people during the past week or anticipate any problems in the upcoming week. 
The therapist then individually asks each group member if they have a topic or concern that they would like to put on the agenda to discuss during the current session. The group member is then asked to give a very brief ( 1 - 3 minute) description of the agenda item. If the group member does not have any agenda items that he or she would like to discuss, then the therapist reminds the patient that if he or she thinks of something during the course of the session he or she is invited to add the topic or concern to the agenda if time permits.

After each group member has had the opportunity to put a topic or concern on the agenda, each agenda item is discussed in turn. If there are too many agenda items for the time alloted, less pressing items are tabled for the next group session. Typical problems may include (1) a recent disagreement or misunderstanding with a parent, spouse, or friend, (2) an upcoming job or housing placement interview, (3) an upcoming date, social or family gathering, (4) a recent failure at an attempt to start a friendship with someone, (5) a recent failure at a social interaction.

Throughout the course of the discussions, the therapist searches for themes in the agenda items in order to assist in generalizing learning and to try to move through the agenda in an efficient manner. For example, one agenda item might be difficulty getting along with a boss while a second agenda item may be conflicts with a 
teacher. A theme that would surface from these two agenda items would be coping and dealing effectively with conflict concerning an authority figure. A second example could be an agenda item that regards a recent fight with a close friend while a second agenda item concerns a misunderstanding with a fellow employee at work. A theme that would surface from these two agenda items is repairing the damage to a friendship or relationship after a fight or misunderstanding.

The therapist also attempts to discourage any group members from monopolizing the discussions and tries to maximize fairly equal participation among group members. Further, the therapist strongly discourages any insulting or unsupportive remarks by group members towards other group members.

Role plays are used as much as possible for all agenda items. Fellow group members can act as parents, spouses, friends, neighbors, etc. in the role plays. Move chairs around as necessary in order to maximize a realistic setting. Often, group members will be reluctant to participate in role plays. It is crucial that the therapist work at encouraging and reinforcing group members for even poor attempts at participation. The therapist must work at creating and maintaining a safe and positive environment in the group. Also, no group member should be allowed to never participate in role plays. 
Reminding group members that this is a crucial part of their treatment and making the experience as pleasurable as possible will reduce group member resistance.

Topics and Themes Approach

Unlike the agenda approach discussed above, this approach utilizes various topics and themes that the therapist develops and designs in order to help the group learn and practice specific social skills. The group may vote on which topics and themes they would like to work on first, second, etc. Each topic or theme could be worked on for as many sessions as the therapist and/or group feel is necessary. Returning to a specific topic or theme weeks or months after it was discussed is also appropriate. A recommended list of typical topics and themes follows along with examples of how these topic could be worked on in the group sessions:

\section{(1) HOW TO START A CONVERSATION}

Role play typical conversation starters in places where people are likely to meet for the first time (e.g., first day at work, meeting a new neighbor, meeting someone for the first time at church or at an entertainment event). Practice a conversation that will last one minute and gradually work towards conversations lasting 5 minutes and longer.

(2) HOW TO KEEP A CONVERSATION GOING

Practice role plays where conversations must last for a certain number of minutes. Help the group develop 
methods of keeping a conversation going by talking about the weather, current events, their appearance, asking lots of questions, etc.

(3) HOW TO END A CONVERSATION

Practice finding ways to terminate conversations using body langauage and phrases such as "It was nice seeing you, I'll look forward to seeing you again soon" or "Take care, say hello to so-and-so for me." Practice learning to "read other people signals" that they want to terminate the conversation.

(4) HOW TO SAY "NO" (to drugs, alcohol, people asking for money or unreasonable favors)

Role play situations where peers, friends, salepeople, etc. ask for something or make requests that are uncomfortable or inappropriate. Examples include a pushy sales person, someone cuting in line, peers encouraging the use of drugs, someone asking for a favor or for money.

(5) HOW TO ASK FOR A FAVOR

Role play asking others for favors or other requests. Examples include asking someone for a ride to some event, asking a boss for a raise in pay or a day off from work. (6) GIVING AND RECEIVING COMPLIMENTS GRACIOUSLY

Practice going around the room giving and receiving compliments. Examples include commenting on a fellow group member's attire or a recent insightful and 
supportive comment.

(7) MAKING INTRODUCTIONS

Role play meeting people at various events or locations and introducing someone to a third friend. Examples include meeting someone in the supermarket, at church, at a sporting event, at work, or on the street. Practice using appropriate phrases such as, "Have you met my good friend John?" "It was a pleasure meeting you." "I've heard a lot about you."

(8) INTERVIEWS (for jobs, group homes, etc.)

Role play various type of interviews for jobs, housing placements, etc.

(9) COPING WITH SHYNESS

Have the group list ways that one can cope with shyness. Role play trying to "bring out" a shy person. (10) HOW TO TELL A JOKE

Practice telling jokes. Discuss delivery, what makes a good vs a bad joke. Find a number of jokes and place them in a hat or box. Group members can pick a joke out of the box and practice telling it.

\section{(11) LISTENING SKILLS}

Tell a story of about 5 to 10 minute duration. Have the group listen carefully to the story and try to recall as many details as possible. Discuss ways of improving listening and reasons why listening is difficult. Have group members role play good listening skills and discuss how they can detect when someone is listening or not. 
(12) NONVERBAL SOCIAL SKILLS (e.g., eye contact, body posture, smiling, voice projection)

Discuss nonverbal social skills such as eye contact, body posture, voice projection, smiling, nodding, the use of hands in conversations, etc. Role play conversations and discuss the nonverbal skills and messages that they behaviors give.

(13) HOW TO ASK SOMEONE FOR A DATE

Role play asking someone for a date. Focus on body posture and nonverbal skills. Discuss how to handle rejection of a request and role play such situations.

Each topic maximizes the use of role plays and can be adapted to the needs and concerns of the group. Additional topics or more indepth coverage of any topic can be utilized in accordance with the needs of the group membership. Throughout all topics and themes, it is important to focus on nonverbal skills and to reinforce group members for their participation and attempts. Discussing how group members can apply these skills outside of the group session should also be encouraged.

\section{Ending each Session}

Each group session is ended with a brief review of the themes or skills discussed and reinforcement of the groups' willingness to practice these skills. The group is encouraged to practice the skills discussed between 
sessions and to report their progress back to the group. Announcing what the topic for the following group session (if the topics and themes approach is being used) should also be conducted by the therapist. The therapist should model good social skills throughout the sessions.

\section{References}

Monti, P.M., Corriveau, D.P., \& Curran, J.P. (1982). Social skills training: Treatment and outcome. In Curren, J.P. and Monti, P.M. (Eds.) Social Skills Training: A Practical Handbook for Assessment and Treatment. New York, NY: Guilford Press.

Monti, P.M., Curran, J.P., Corriveau, D.P., Delancey, A.L., \& Hagerman, S.M. (1980). The effects of social skills training groups and sensitivity training groups with psychiatric patients. Journal of Consulting and Clinical Psychology, 48, 241-248.

Yalom, I.D. (1983). Inpatient Group Psychotherapy. New York, NY: Basic Books. 